\title{
Study on the early larval development and growth of the red porgy, Pagrus pagrus with emphasis on the mass mortalities observed during this phase*
}

\author{
ALEXIS J. CONIDES ${ }^{1}$ and BRANKO GLAMUZINA² \\ ${ }^{1}$ National Centre for Marine Research, Athens 166 04, Greece. E-mail: conides@posidon.ncmr.gr \\ ${ }^{2}$ Institute of Oceanography and Fisheries, Laboratory for Ecology and Aquaculture, POB 83- Akvarij, Damjana Jude 12, \\ 20000 Dubrovnik, Croatia.
}

\begin{abstract}
SUMMARY: The purpose of this study was to determine the early growth scheme and development stages of the red porgy, Pagrus pagrus larvae through the transition from endogenous and exogenous food sources using as main criterion the body length gained at each development stage. The initial period of the species' larval life can be divided into three phases: a) an initial phase characterised by no motility $(0-24 \mathrm{~h}$ time after hatching; TAH); b) a phase characterised by active movement and exploitation of the endogenous food reserves (24 h to $96 \mathrm{TAH})$; and c) a phase characterised by the transition from endogenous to exogenous food (96 to $168 \mathrm{TAH}$ ). It was observed that there does not exist an overlapping period between phases $b$ and $c$ and therefore, there exists a gap of 24-36 hours during which the larvae have exhausted their internal food reserves (oil globule and yolk sac) while the digestive tract is not ready to digest external food items (rotifers). We observed a massive larval mortality reaching almost $85 \%$ between days 3 and 7 after hatching.
\end{abstract}

Key words: Pagrus pagrus, larval morphology, growth, efficiency of development, mortality.

\section{INTRODUCTION}

The protandrous hermaphrodite species Pagrus pagrus (Sparidae) is an important commercial species for the Mediterranean fishery. Recently, it has been considered as a candidate for aquaculture to aid the process of increasing the diversification of aquaculture products in the region (Conides et al., 1996; Conides and Nengas, 1998). Although, a lot of research has been conducted on the reproduction and cultivation of the commonly cultivated species -European sea bass and Gilthead sea bream (i.e.;

*Received July 11, 2000. Accepted January 9, 2001.
Marangos et al., 1986; Conides and Anastasopoulou, 1992; Klaoudatos and Conides, 1996; Conides and Parpoura, 1995)- very little is known about the red porgy, especially considering early life stages. Research is limited to description of larval and growout rearing efforts in the commercial hatchery (Kolios et al., 1997) and development of the larval visual system (Roo et al., 1999). Conversely, the Japanese species Pagrus major has been extensively studied for its fishery management (Matsuyama et al., 1988; Foscarini, 1988) and is the second most commonly cultured marine fish in Japan after yellowtail (Foscarini, 1988). The first attempts to reproduce and cultivate the species for 
aquaculture purposes in the Mediterranean showed that there exist significant problems that have prevented the mass production of the species. These problems are mainly related to the significant mortality observed during the larval stages as well as the dark skin coloration of the reared fish.

The aim of the present study is to record the various morphological stages of the Pagrus pagrus larval development. The larval shape and morphological development were recorded while the growth rates and the yolk sac and oil globule absorption rates were quantified. In addition, the survival rates were measured and analysed in order to describe the life history profile of the species during the first days after hatching.

\section{MATERIALS AND METHODS}

The specimens used in the present study were obtained from spontaneous spawning in the laboratory. Immediately after spawning the pelagic eggs were collected with a planktonic net $500 \mu \mathrm{m}$ mesh and transferred to rectangular PVC tanks with a capacity of $1 \mathrm{~m}^{2}$ each. The sea water temperature throughout the experiment was kept at $18^{\circ} \mathrm{C} \pm 0.3$ using $300 \mathrm{~W}$ glass submersible thermostats. Salinity varied between 37 and 38.2\%o. The larvae were initially fed on rotifers Brachionus plicatillis which had been fed on yeast and unicellular algae (Chlorella sp., Tetraselmis suecica). The rotifers were present in the tanks from the start of the experiment at densities reaching 60 individuals $\mathrm{ml}^{-1}$.

The experiment was carried out in duplicate. Two experimental tanks were stocked with 50,000 larvae each. Sampling was carried out in 12-hour intervals until $192 \mathrm{~h}$ after hatching. At each interval, 150 larvae were collected from each tank. The total length (TL), the length of both yolk sac axes (L, major axis; $\mathrm{H}$, minor axis) as well as the diameter (d) of the oil globule were measured for each individual, using a M5-A Wild stereomicroscope with ocular micrometer lens reading to the nearest $0.01 \mathrm{~mm}$. All observations were carried out on live specimens (Klaoudatos et al., 1990). The yolk sac volume $\left(\mathrm{V}_{\mathrm{ys}}\right)$ and oil globule $\left(\mathrm{V}_{\mathrm{og}}\right)$ volumes were calculated using the formulae proposed by Blaxter and Hempel (1966) and Cetta and Capuzzo (1982) considering the yolk sac as an ellipse and the oil globule as a sphere:

$$
V_{y s}=\frac{4}{3} \pi \frac{L}{2}\left(\frac{H}{2}\right)^{2} \text { and } V_{o g}=\frac{4}{3} \pi\left(\frac{d}{2}\right)^{2}
$$

where $\mathrm{L}$, is the longest axis of the ellipse, $\mathrm{H}$, is the smaller (vertical) axis of the ellipse and d, the diameter of the sphere (in $\mathrm{mm}$ ).

Using the average values of the above measurements and calculations, the growth rate ( $\mathrm{g}$, the mean increase of length per hour) and the yolk sac utilisation rate ( $\mathrm{u}$, the mean decrease of yolk sac volume per hour) were calculated according to the following equations:

$$
\begin{aligned}
& g=\frac{\text { Length }_{i}-\text { Length }_{i-1}}{t \frac{\text { Length }_{i}-\text { Length }_{i-1}}{2}} 100 \\
& u=\frac{V y s_{i}-V y s_{i-1}}{t \frac{V y s_{i}-V y s_{i-1}}{2}} 100
\end{aligned}
$$

where: i, refers to the measurement at the end of period i; i-1, refers to the measurement at the start of period $\mathrm{i}$; and $\mathrm{t}$ is the time elapsed between successive measurements (12 or 24 hours) (Klaoudatos et al., 1990). The efficiency of development was calculated according to the formula proposed by Klaoudatos et al. (1990): $\mathrm{Ed}=\mathrm{u} / \mathrm{g}$. The statistical significance of the means was examined using ANOVA test.

Growth of the larvae was correlated with time (hours after hatching) according to the following standard equations:

$$
\begin{array}{ll}
\text { von Bertallanfy: } & L=L_{\max }\left[1-e^{-b(t+c)}\right] \\
\text { Gompertz: } & L=a \cdot e^{e^{-b-c t}}
\end{array}
$$

Logistic:

$$
L=\frac{a}{1+b e^{-c t}}
$$

where $L$ is the length estimate at any given interval; $L_{\max }$ is the maximum length reached during the studied period (mm); and $a, b, c$ are the coefficients to be calculated using size at time intervals data according to the Powell-Wetherall method (Powell, 1979; Wetherall, 1986; FAO, 1997).

The relationship between growth rate and time after hatching for the porgy larvae during this life stage was also calculated using the basic growth equations of von Bertallanfy, Gompertz and the logistic (Ricker, 1979; Hopkins et al., 1988) for comparison with other references. Heartbeat rate was measured on live larvae under a dissection microscope. The larvae were placed under the microscope only at the time of measurement and for 1 minute in order to avoid changes of heartbeat rate due to the extreme conditions under a microscope (temperature, light).

Mortality measurement is difficult when dealing with larvae during the first days of life since their 
bodies are extremely fragile and dead larvae decompose very rapidly. For added accuracy, during the present experiment, mortality was estimated by comparing the results of two different methods. At first, the bottom of the rearing tanks was siphoned gently on a 12-hour basis by means of a plastic tube with a small opening in order to avoid high pressure suctioning and the siphoned water was passed through a $200 \mu \mathrm{m}$ plankton net for keeping the dead larvae. Mortality was estimated by counting the dead larvae kept by the plankton net. In addition, 10 countings of live larvae were performed using a 1-L beaker from 10 different positions in the rearing tanks and a variety of depths. The rearing density was calculated as the mean of the 10 samplings. By comparing the 2 values obtained, the error of estimation due to decomposed dead larvae was reduced significantly. Statistical analysis of mortality results in both tanks were compared using one-way ANOVA test.

\section{RESULTS}

\section{Morphological development}

The eggs of the red porgy are spherical with a mean diameter of $834 \pm 21 \mu \mathrm{m}$. Hatching occurred after 50 hours at $18^{\circ} \mathrm{C}$ at a rate of $84 \%$. Newly hatched larvae of $P$. pagrus have a mean total length of $3.020 \mathrm{~mm}$. The body of the larva is curved at the head region, the eyes are unpigmenetd and the mouth is undifferentiated. The digestive tract is visible as a straight thin tube over the yolk sac while the anus is closed. The larvae do not move during the first 24 hours. The body of the larva is surrounded by the primordial fin. Dark field microscopy revealed that the larvae exhibit xanthophore stellate cells along the base of the primordial fin at the dorsal side while there exists a xanthophore belt between myomeres 22 and 24 . Finally there are also 2-3 chromophore cells on the yolk sac and the oil globule and several others randomly located on the lateral parts of the body. At the $12 \mathrm{~h}$ TAH stage, larvae have the same morphological characteristics as the newly hatched larvae but their mean total length is $3.13 \mathrm{~mm}$. At the $24 \mathrm{~h}$ stage the total length of the larva is $3.20 \mathrm{~mm}$. The otoliths become visible at the head region. The heart is visible and the mean heartbeats are $80 / \mathrm{min}$. The pigmentation pattern has not changed. The head region has been separated from the yolk sac and the body is almost straight.
At the $48 \mathrm{~h}$ stage, the mean total length of the larva is $3.30 \mathrm{~mm}$. The blood circulation is not yet visible but the heartbeats increase to $170 / \mathrm{min}$. The eye lens is visible but the eyes are not pigmented yet. The convolution process of the digestive tract has started. The primordial fin is still not divided. At the $72 \mathrm{~h}$ stage, the mean total length of the larva is $3.56 \mathrm{~mm}$. The eyes become pigmented and move. The mouth is opened and the mandible is moving. The digestive tract convulses. The heartbeat remains high at $163 / \mathrm{min}$. The xanthophore cell belt located between the myomeres 20 and 25 have disappeared. The primordial fin is still whole. The pectoral fins first appear and are functional.

At the $96 \mathrm{~h}$ stage, the mean total length of the larva is $3.65 \mathrm{~mm}$. The edge of the primordial fin is serrated. The blood circulation is visible. The chromophores have been reduced while the xanthophore cells have disappeared. Only a small part of the oil globule still remains. At the $120 \mathrm{~h}$ stage, the mean total length of the larva is $3.8 \mathrm{~mm}$. The mouth and the digestive tract are functional and food particles appear for the first time. The heartbeat increases considerably and reaches 208/ $\mathrm{min}$. The organs and the dense blood circulation around them are visible. The yolk sac and the oil globule have disappeared. The edge of the primordial fin is still serrated but the fin is not divided yet except a small notch appearing just behind the head region. At the $144 \mathrm{~h}$ stage, the mean total length of the larva is $4.0 \mathrm{~mm}$. Traces of the tail fin rays appear. Also the olfactory organ is visible on the snout of the larva. The chromophore cells disappear except some randomly located along the digestive tract.

At the $192 \mathrm{~h}$ stage, the larva total length is 4.05 $\mathrm{mm}$. The digestive tract is ready, fully functional and full of food items. The lateral arteries of the body are visible. The body is composed of 25-26 myomeres. The heartbeats remain high at $184 / \mathrm{min}$.

The various measurements and calculations from the duplicate experiment (including standard deviations) obtained during the experiments are summarised in Table 1.

\section{Growth rates and food utilisation}

The growth of the larvae in length is illustrated in Figure $1 \mathrm{~A}$. The average length gain ranges between $0.001 \mathrm{~mm} / \mathrm{h}$ and $0.008 \mathrm{~mm} / \mathrm{h}$ throughout the period. The maximum gain was observed during the $72 \mathrm{~h}$ TAH stage $(0.011 \mathrm{~mm} / \mathrm{h})$. Also the logarithmic representation of the growth (Fig. 1B) shows that the 
TABLE 1. - Data on the growth parameters estimated for red porgy, Pagrus pagrus larvae $(\mathrm{n}=2 \mathrm{x} 150, \mathrm{P}<0.01)$

\begin{tabular}{|c|c|c|c|c|c|c|c|c|c|c|c|c|c|c|c|}
\hline \multirow{3}{*}{$\begin{array}{l}\text { TAH } \\
\text { Hours }\end{array}$} & \multirow{2}{*}{\multicolumn{2}{|c|}{ TL, }} & \multicolumn{4}{|c|}{ Yolk sac dimensions } & \multirow{2}{*}{\multicolumn{2}{|c|}{$\begin{array}{c}\text { Oil globule } \\
\text { dimensions } \\
\text { Diameter }\end{array}$}} & \multirow{2}{*}{\multicolumn{2}{|c|}{ Vys }} & \multirow{2}{*}{\multicolumn{2}{|c|}{ Vog }} & \multirow[b]{3}{*}{$\mathrm{g}$} & \multirow[b]{3}{*}{$\mathrm{u}$} & \multirow[b]{3}{*}{$\mathrm{Ed}$} \\
\hline & & & \multicolumn{2}{|c|}{ Length } & \multicolumn{2}{|c|}{ Height } & & & & & & & & & \\
\hline & $\mathrm{mm}$ & $\mathrm{SD}$ & $\mathrm{mm}$ & SD & $\mathrm{mm}$ & SD & $\mathrm{mm}$ & SD & $\mathrm{mm}^{3}$ & $\mathrm{SD}$ & $\mathrm{mm}^{3}$ & $\mathrm{SD}$ & & & \\
\hline 0 & 3.020 & 0.120 & 1.160 & 0.010 & 0.640 & 0.140 & 0.300 & 0.050 & 0.249 & 0.090 & 0.110 & 0.006 & - & - & - \\
\hline 12 & 3.130 & 0.140 & 1.134 & 0.050 & 0.466 & 0.110 & 0.310 & 0.050 & 0.129 & 0.020 & 0.110 & 0.005 & 0.2981 & 0.3252 & 1.1 \\
\hline 24 & 3.200 & 0.200 & 1.100 & 0.030 & 0.350 & 0.090 & 0.300 & 0.040 & 0.070 & 0.001 & 0.110 & 0.004 & 0.1843 & 0.1553 & 0.8 \\
\hline 48 & 3.300 & 0.150 & 0.490 & 0.085 & 0.260 & 0.060 & 0.300 & 0.040 & 0.017 & 0.004 & 0.110 & 0.007 & 0.1282 & 0.0679 & 0.5 \\
\hline 72 & 3.560 & 0.240 & 0.000 & - & 0.000 & - & 0.150 & 0.030 & 0.000 & - & 0.014 & 0.002 & 0.3158 & 0.0207 & 0.1 \\
\hline 96 & 3.650 & 0.300 & & & & & 0.000 & & & & 0.000 & & 0.1040 & 0.0 & 0.0 \\
\hline 120 & 3.800 & 0.198 & & & & & & & & & & & 0.1678 & & \\
\hline 144 & 4.000 & 0.470 & & & & & & & & & & & 0.2137 & & \\
\hline 192 & 4.050 & 0.290 & & & & & & & & & & & 0.0259 & & \\
\hline
\end{tabular}

where: TAH: time after hatching; TL: total length, SD: standard deviation; Vys: Yolk sac volume; Vog: Oil globule volume; g: growth rate (\% of TL/day); u: yolk sac utilisation rate $\left(\%\right.$ of $\left.\mathrm{V}_{\mathrm{ys}} / \mathrm{d}\right)$; Ed: Efficiency of Development (u/g)
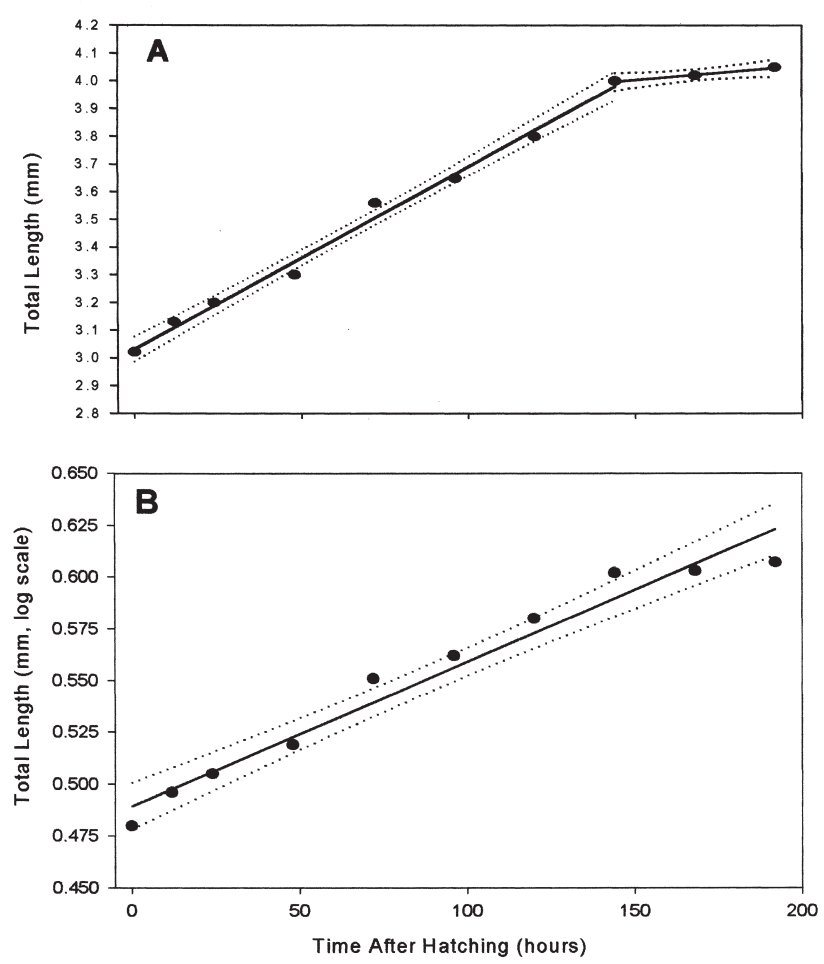

FIG. 1. - Relationship between total body length and time after hatching for Pagrus pagrus Larvae. A, normal scale; B, log scale (dotted curves denote $95 \%$ confidence limits of the regression)

growth rate is constant for the first $144 \mathrm{~h}$ TAH and then it levels out i.e. growth in length seems to stop momentarily ("broken stick" appearance)

The calculation of the parameters of the standard growth curves gave the following growth equations ( $\mathrm{t}$ between 0 and 192 hours TAH).

von Bertallanfy: $L=4.595\left[1-e^{-0.006(t+185.92)}\right.$, $r^{2}=0.9784$, Std. error $= \pm 0.08 \mathrm{~mm}$

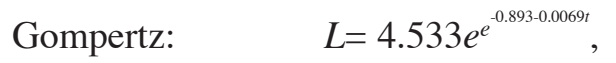
$r^{2}=0.989$, Std. error $= \pm 0.044 \mathrm{~mm}$
Logistic: $\quad L=\frac{4.4301}{1+0.472 e^{-0.0085 t}}$,

$$
r^{2}=0.989, \text { Std. error }= \pm 0.066 \mathrm{~mm}
$$

The results show that the larvae reach an approximate length of $4.564 \pm 0.04 \mathrm{~mm}$ in total length.

The oil globule and the yolk sac reserves are exhausted rapidly (Fig. 2A) until the $72 \mathrm{~h}$ and $96 \mathrm{~h}$ TAH stage respectively. An important observation is that the yolk sac consumption starts almost immediately after hatching while the oil globule consumption starts when the yolk sac is almost absorbed. The equations that describe the change of the yolk sac and oil globule volumes $\left(\mathrm{V}_{\mathrm{ys}}, \mathrm{V}_{\mathrm{og}}\right.$, in $\left.\mathrm{mm}^{2}\right)$ in time $(\mathrm{t}$, hours) are:

$$
\begin{aligned}
& \begin{array}{l}
\mathrm{V}_{\mathrm{ys}}=0.102+0.002 \cdot \mathrm{t}-0.00007 \cdot \mathrm{t}^{2}+0.0000004 \cdot \mathrm{t}^{2} \\
\mathrm{r}^{2}=0.956, \text { std. err. }= \pm 0.02 \mathrm{~mm}^{2}
\end{array} \\
& \text { and } \\
& \qquad \begin{array}{c}
\mathrm{V}_{\mathrm{og}}=0.248-0.011 \cdot \mathrm{t}+0.0002 \cdot \mathrm{t}^{2}-0.000001 \cdot \mathrm{t}^{2} \\
\mathrm{r}^{2}=0.999, \text { std. err. }= \pm 0.006 \mathrm{~mm}^{2}
\end{array}
\end{aligned}
$$

Statistical results showed that there was not a significant difference between the experimental tanks.

\section{Efficiency of development and initial feeding}

The efficiency of development (Ed) was calculated until the $96 \mathrm{~h}$ TAH stage when the yolk sac and oil globule are fully absorbed (Fig. 2B). The larvae consume rotifers actively at the $120 \mathrm{~h}$ TAH stage and therefore, there exists a minimum gap of $24 \mathrm{~h}$ during which the larvae have no food reserves (endogenous or exogenous) available. The rapid consumption of the internal reserves (yolk sac and oil globule) is reflected in the profile of Ed parameter (Fig. 2B). 

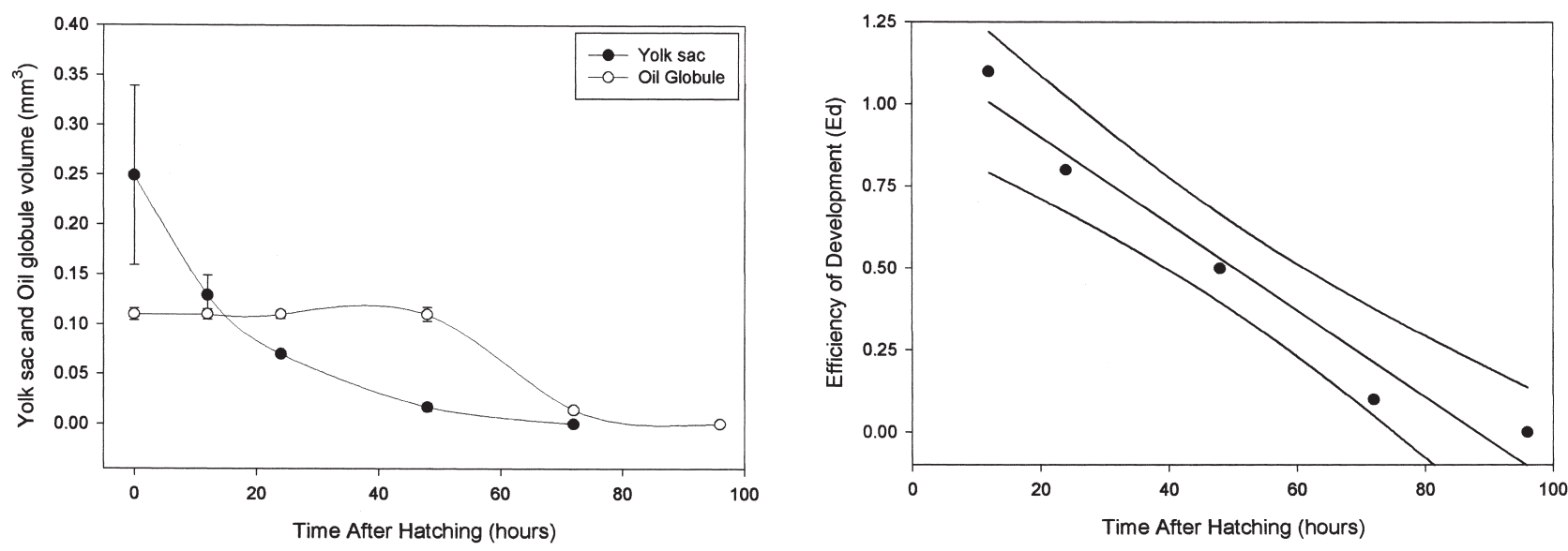

FIG. 2. - A. Yolk sac (Vys) and oil globule (Vog) volume decrease for the Pagrus pagrus larvae. B. Relationship between the efficiency of development and time after hatching for the Pagrus pagrus larvae (curved lines denote 95\% confidence limits of the regression).

\section{Mortality}

From the density counts it is evident that the profile of the resulting curve exhibits two different inflection points (i.e. it is sigmoidal) indicating that the rate of mortality increase changes twice during the studied period (Fig. 3). The first segment of the density curve shows a smooth decreasing trend lasting 24 hours after hatching. After this period, mortality increases substantially and rapidly reaches a low value during the period from 72 and 120 hours after hatching. This is when the internal food reserves (yolk sac and oil globule) are exhausted until the first food item appears in the digestive track (120 hours after hatching). During the period between 24 hours and 120 hours after hatching, almost the $85 \%$ of the population has been lost (Fig.
3). After the milestone of 120 hours after hatching, the surviving larvae show appetite and the digestive tract appears full with rotifers. The terminal survival remains almost stable at $6.65 \pm 0.63 \%$. In addition, as shown in Figure 3, the standard deviation of the mean density reduces over time. No significant difference between the density calculations was found and therefore, the mean valued from both tanks was used for further analysis and discussion.

\section{DISCUSSION}

The data presented in this paper show several interesting characteristics of the red porgy that distinguish it from other cultivated species. The egg diameter is similar to that reported by other authors

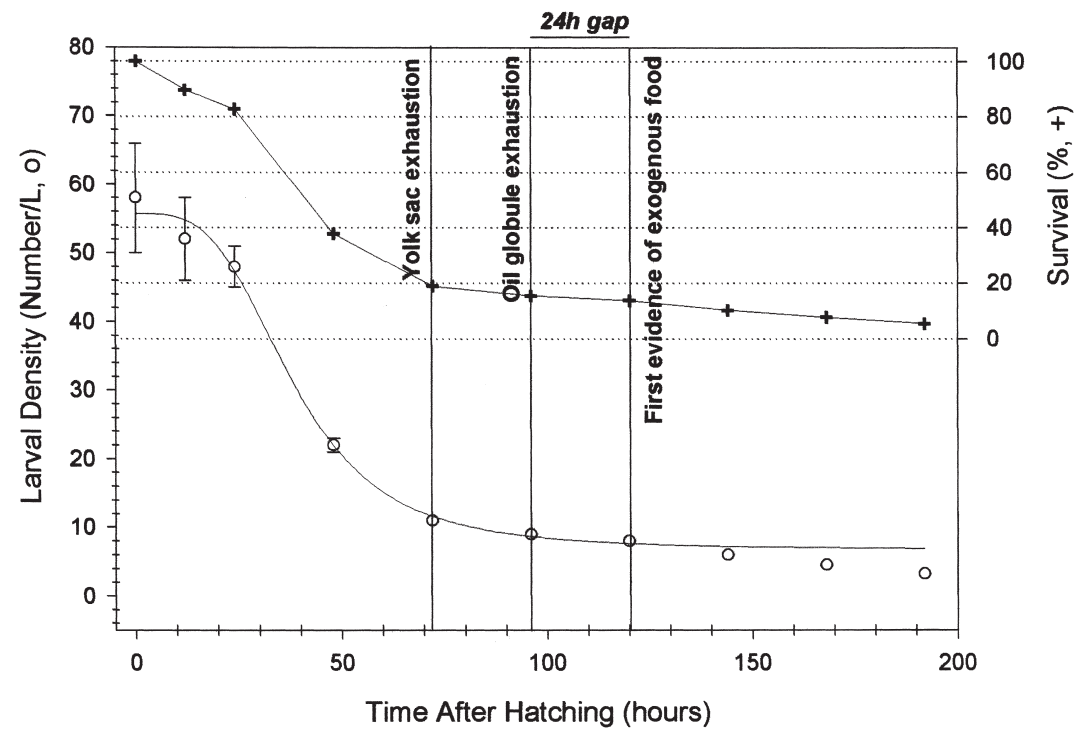

FIG. 3. - Rearing Density (Number of larvae per L) and survival curves of the red porgy, Pagrus pagrus larvae during eight days experimental period. 
(Kolios et al., 1997; Manooch, 1976) The hatching period is 50 hours at $18^{\circ} \mathrm{C}$ which is not in accordance with other authors (Kolios et al., 1997) who reported that the hatching period is 60 hours at $18^{\circ} \mathrm{C}$. The difference may be explained by the fact that these authors stocked the eggs in an outdoor 15 $\mathrm{m}^{3}$ tank with mesocosm algal system where it is possible that the eggs encountered diurnal changes of temperatures other than the mean of $18^{\circ} \mathrm{C}$, and this contributed to the increase of the hatching time. The same authors reported that the hatching started at 60 hours after fertilisation and concluded after 85 hours. The hatching percentage was estimated at $84 \%$ and is similar to that reported by Kolios et al. (1997).

The size of the newly hatched $(3.02 \mathrm{~mm})$ larva is very similar to that of gilthead sea bream $(2.95 \mathrm{~mm})$ and is smaller than that of the European sea bass (3.20 mm) (Klaoudatos et al., 1990; Barnabé et al., 1976) and Chelon labrosus (4 mm; Boglione et al., 1992). Red porgy larvae are longer than the larvae of some other potential candidates of the Mediterranean aquaculture: i.e. Epinephelus marginatus (1.52 mm; Glamuzina et al., 1998), Epinephelus costae (1.76 mm; Glamuzina et al., 2000), Lithognathus mormyrus (1.7 mm; Divanach and Kentouri, 1983), Puntazzo puntazzo (1.69 mm; Faranda et al., 1985), Dentex dentex (2.17 mm; Glamuzina et al., 1989) and Diplodus vulgaris (2.63 $\mathrm{mm}$; JugDujakovic and Glamuzina, 1988), and therefore easier to culture during early larval stages.

A two-phase pattern of growth exists for the Pagrus pagrus larva. The high growth rate which occurs during the first hours after hatching can be explained by the rapid decrease of the yolk sac. It has also been reported that the red porgy exhibits a rather small yolk sac and thus, the larva must start feeding as soon as possible after hatching (Roo et $a l ., 1999)$. Rapid early growth is reported for many pelagic fish (Kohno et al., 1986). The rapid growth phase is followed by a low-growth phase in terms of length increase rate. This low-growth phase starts a few hours after the depletion of the internal food reserves. Klaoudatos et al. (1990) argued that this low-growth rate phase characterises the larval development and the increased growth rates are owing to the alignment of the head region, since the measured parameter is the length of the larva. However, the duration of these phases is very long to support this and therefore, the changes of the observed growth rate should be attributed to the metabolic processes and transition between internal differentiation and external morphogenesis occurring during this period. The slow-growth phase is also associated with very high mortalities since it is observed that although the mouth is open, the first food particles appear later $(120 \mathrm{~h} \mathrm{TAH})$. The observed growth rates of the larvae are much lower than other species such as the European sea bass, which reaches $5.63 \mathrm{~mm}$ at $144 \mathrm{~h} \mathrm{TAH}$, and the Gilthead sea bream, which reaches $5 \mathrm{~mm}$ at $12 \mathrm{~h}$ TAH (Klaoudatos and Apostolopoulos, 1986; Klaoudatos et al., 1990).

The growth profile is in accordance to the observed Efficiency of Development. The Ed falls continuously and reduces to 0 simultaneously with the exhaustion of food reserves giving an indication of the importance of the internal food reserves for the development of the larvae. Additionally, it is a significant milestone for larval development. The Ed parameter never reaches 0 for European sea bass larvae (Klaoudatos et al., 1990) indicating that the overlapping period between the exhaustion of internal food reserves and the use of external food (rotifers) is adequate for the acclimation of the larvae to external feeding. However when the Ed parameter reaches 0 , then it is obvious that the energy from food has been eliminated and subsequently, larval mortality increases dramatically. Further investigation is required on the $\mathrm{Ed}$ of other fish in order to depict its usefulness as an indicator of energy levels in larva.

The rapid consumption of the internal reserves of the $P$. pagrus larvae and the observed slow development of internal organs indicate that there exists a time gap, 24-36 hours long, between the exhaustion of internal reserves and the stage when the larva is capable of consuming and utilising external food items, namely rotifers. This is justified by the fact that there exists an interval of at least $24 \mathrm{~h}$ between the exhaustion of the oil globule and the appearance of food items in the digestive tract. Such a characteristic has never been reported for other species and especially species that are used for aquaculture (Klaoudatos et al., 1990). On the contrary, it has been reported that there exists an overlapping period lasting approximately 24 to $48 \mathrm{~h}$-depending on the species- during which the acclimatization of the larvae to exogenous food can be accomplished while a part of the yolk sac and the oil globule still remain intact (i.e. sea bass, Klaoudatos et al., 1990; Dentex dentex, Glamuzina et al., 1989; Diplodus vulgaris, Jug-Dujaković and Glamuzina, 1988). Also for salmonids and catfish, this overlap may be comparatively long (eg. weeks; Eda, et al., 1990) 
The observed results on mortality and their explanation are not in accordance with Kolios et al. (1997) who reported that the first peak of mortality occurs between 9-12 days after hatching (216-288 $\mathrm{h}$ after hatching) and they explained that this is owed to the fact that some larvae cannot adapt to the consumption or digestion of rotifers. However, they reported that the larvae consumed rotifers from day 3 after hatching and we may conclude that their explanation cannot be justified since a larva cannot survive for 6 to 9 days after hatching without being able to utilise external food items. Based on the aforementioned authors, the observed mortality should not be considered normal and therefore, other reasons such as temperature fluctuations, should be discussed to explain these observations. However the mortality observed during the initial stages of life of the porgy is owed both to physical parameters as well as biological. According to our observations the mouth of the porgy is very small in comparison with other species such as the sea bass and seabream and therefore, the traditional methods of rearing larvae do not apply. In particular, the typical S- and L- strain rotifers cannot be consumed by the larva until the $5^{\text {th }}$ day after hatching due to the fact that the larva has a small mouth opening. Besides, the experimental temperature was kept constant at $18^{\circ} \mathrm{C}$ and therefore, the possibility that this mortality may be owed to temperature fluctuations does not apply. Since more information has not been published on this species, the observed mortality cannot be sufficiently explained and therefore, the hypothesis that can be set herein is that probably the mortality is owed to a combined developmental asynchrony dependent on rearing temperature level (but not fluctuations) and natural development rates. This indicates that further research is required on optimal temperature for the egg hatching and larval rearing, at least for the first 7 days after hatching as well as to identify and develop new smaller live food organisms similar to the natural diet of the species such as copepods.

\section{REFERENCES}

Barnabé, G., F. Boulineau-Coatanea and F. René. - 1976 Chronologie de la morphogenèse chez le loup ou bar Dicentrarchus labrax (L.) (Pisces, Serranidae) obtenu par reproduction artificielle. Aquaculture, 8: 351-363.

Blaxter, J.H.S. and G. Hempel. - 1966. Utilization of the yolk by herring larvae. J. Mar. Biol. Assoc. UK, 46: 219-234.

Boglione, C., B. Bertolini, M. Russiello and S. Cataudella. - 1992. Embryonic and larval development of the thick-lipped mullet (Chelon labrosus) under controlled reproduction conditions.
Aquaculture, 101: 349-359.

Cetta, C.M. and J.M. Capuzzo. - 1982. Physiological and biochemical aspects of embryonic and larval development of the winter flounder, Pseudopleuronectes americanus. Mar. Biol., 71: 327-337.

Conides, A. and K. Anastasopoulou. - 1992. Report of observations on the point-no-return of fishes studying the gilthead sea bream Sparus aurata juveniles in starvation. FRESENIUS Env. Bulletin, 2(9): 514-516.

Conides A. and A. Parpoura. - 1995. Review on biology and cultivation of the gilthead sea bream, Sparus aurata L. 1758, in the Mediterranean. Dept. of Aquaculture, National Centre for Marine Research, Athens, sp. ed., pp. 34.

Conides, A., A. Parpoura and M. Pagonis. - 1996. Aquaculture in the Mediterranean. In: Prof. Atig Huni, M. (ed.), Development and appraisal of aquaculture in Libya. Proceedings of the seminar on the appraisal of aquaculture in Libya, November 23-25, 1996, Surt, Libya, 37 p.

Conides, A. and I. Nengas. - 1998. Description and analysis of the fisheries and aquaculture sector of Greece (1985-1997). Greek Fishing News, 195, 158-175 (in Greek).

Divanach, P. and M. Kentouri. - 1983. Donee preliminaires sur la technique de production, la croissance et la survie des larves de marbre, Lithognathus mormyrus. Aquaculture, 31: 245-256.

Eda, H., R. Murashige, Y. Oozeki, A. Hagiwara, B. Eastham, P. Bass, C.S Tamaru and C.-S. Lee. - 1990. Factors affecting intensive larval rearing of striped mullet, Mugil cephalus. Aquaculture, 91: 281-293.

FAO. - 1997. FAO-ICLARM stock assessment tools. Reference Manual, Comp. Info. Ser., No 8., vol. 1, 75-77.

Faranda, F., A. Cavaliere, G. Lo Paro, A. Manganaro and A. Mazzola. - 1985. Preliminary studies on reproduction of Puntazzo puntazzo (Gmelin 1789) (Pisces, Sparidae) under controlled conditions. Aquaculture, 49: 111-123.

Foscarini, R. - 1988. A review: intensive farming procedure for red sea bream (Pagrus major) in Japan. Aquaculture, 72: 191-246.

Glamuzina, B., J. Jug-Dujaković and I. Katavić. - 1989. Preliminary studies on reproduction and larval rearing of common dentex, Dentex dentex (Linnaeus 1758). Aquaculture, 77: 75-84.

Glamuzina, B., B. Skaramuca, N. Glavić, V.Kožul, J. Dulčić and M. Kraljević. - 1998. Egg and early larval development of laboratory reared dusky grouper, Epinephelus marginatus (Lowe, 1834) (Pisces, Serranidae). Sci. Mar.,62(4): 373-378.

Glamuzina, B., N. Glavić, P. Tutman, V. Kožul and B. Skaramuca. -2000 . Egg and early larval development of laboratory reared goldblotch grouper, Epinephelus costae (Steindachner, 1878) (Pisces, Serranidae). Sci. Mar., 64(3): 341:345.

Hopkins, K.D., M.L. Hopkins and D. Pauly. - 1988. A multivariate model of tilapia growth applied to seawater tilapia culture in Kuwait. ICLARM Conf. Proc., 15: 29-39

Jug-Dujaković, J. and B. Glamuzina. - 1988. Preliminary studies of reproduction and early life history of Diplodus vulgaris (E. Geoffroy Saint-Hilaire, 1817) in captivity. Aquaculture, 69: 367-377.

Klaoudatos S. and A. Conides. - 1996. Growth, food conversion, maintenance and long-term survival of gilthead sea bream, (Sparus aurata L.) juveniles after abrupt transfer to low salinity. Aqua. Res., 27: 765-774.

Klaoudatos, S. and I. Apostolopoulos. - 1986. Experimental results of the reproduction and cultivation of the euryhaline fish, Sparus aurata and Dicentrarchus labrax, under controlled conditions. Proceedings of the $3^{\text {rd }}$ Panhellenic Congress on Oceanography and Fisheries, May 23-25, 1986: 55-64.

Klaoudatos, S., N. Tsevis and A. Conides. - 1990. Energy sources during early larval development of the European Sea Bass, Dicentrarchus labrax (L.), Aquaculture, 87: 361-372.

Kohno, H., S.Hara and Y. Taki, Y. - 1986. Early larval development of the sea bass Lates calcarifer with emphasis on the transition of energy sources. Bull. Japan Soc. Sci. Fish., 52(10): $1719-1725$

Kolios, P., S. Kiritsis and N. Katribusas. - 1997. Larval-rearing and growout of the red porgy (Pagrus pagrus) in the Riopesca hatchery (Greece). Hydrobiologia, 358: 321-325.

Manooch, C.S. - 1976. Reproductive cycle, fecundity and sex ratios of the red porgy, Pagrus pagrus (Pisces: Sparidae) in North Carolina. Fish. Bull., 74, 4.

Marangos, C., H. Yagi and H.J. Ceccaldi. - 1986. Rôle de la température et de la salinité sur le taux de survie et la mor- 
phogenèse au cours de développement embryonnaire chez les oeufs du loup de mer, Dicentrarchus labrax, (Linnaeus, 1758) (Pisces, Teleostei, Serranidae). Aquaculture, 54: 287-300.

Matsuyama, M., R. Torres Lara and S. Matsuura. - 1988. Juvenile bisexuality in the red sea bream, Pagrus major. Envir. Biol. Fish., 21: 27-36.

Powell, D.G. - 1979. Estimation of mortality and growth parameters from length-frequency in the catch. Rapp. P.-V. reun., CIEM, 175: 167-169.

Ricker, W.E. - 1979. Growth rates and models. In: W.S. Hoar and D.J. Randall (eds.), Fish Physiology: Bioenergetics and
Growth, vol. VIII pp. 677-743. Academic Press, New York.

Roo, F.J., J. Socorro, M.S. Izquierdo, M.J. Caballero, C.M. Hernandez-Cruz, A. Fernandez, and H. Fernandez-Palacios. 1999. Development of red porgy Pagrus pagrus visual system in relation with changes in the digestive tract and larval feeding habits. Aquaculture, 179: 499-512.

Wetherall, J.A. - 1986. A new method for estimating growth and mortality parameters from length-frequency data. ICLARM Fishbyte, 4(1): 12-14

Scient. ed.: S. Zanuy 